Article

\title{
Angry Reactionary Narcissists? Anger Activates the Link Between Narcissism and Right-Populist Party Support
}

\author{
Sabrina Jasmin Mayer ${ }^{1,2}$ and Christoph Giang Nguyen ${ }^{3, *}$ \\ ${ }^{1}$ Cluster for Data and Methods, German Center for Integration and Migration Research (DeZIM), Germany; \\ E-Mail: mayer@dezim-institut.de \\ 2 Department of Political Science, University of Duisburg-Essen, Germany \\ ${ }^{3}$ Otto-Suhr Institute, Freie Universität Berlin, Germany; E-Mail: christoph.nguyen@fu-berlin.de \\ * Corresponding author
}

Submitted: 10 January 2021 | Accepted: 25 May 2021 | Published: 27 August 2021

\begin{abstract}
Even though previous research connected personality traits and support for radical-right populist parties (RRP), the question of which mechanisms connect these concepts is still underexplored. In particular, we focus on narcissistic rivalry, a maladaptive path of grandiose narcissism. Drawing on the affective intelligence framework and the narcissistic admiration and rivalry concept, we propose that the effect of rival narcissism on vote choice for the German Alternative für Deutschland is mediated by reactionary political orientations and activated by anger. Drawing on 2017 data from the mixed-mode representative GESIS panel $(N=2,552 \& 1,901)$, we employ moderated mediation analyses. We show that reactionary political orientations mediate the relationship between narcissistic rivalry and RRP support. However, high levels of generalised anger are needed to activate the relationship between personality, reactionary values, and RRP support, whereas the mediating role of anti-immigrant sentiment is not affected by anger. Our study emphasises the role of anger in RRP support, thus showing that anger might explain why only some people with a specific predisposition support RRPs. The study also stresses the complexity of the relationship between personality, value orientations, and political behaviour.
\end{abstract}

\section{Keywords}

anger; emotions; narcissism; reactionary politics; right-populist vote

\section{Issue}

This article is part of the issue "Reactionary Politics and Resentful Affect in Populist Times" edited by Tereza Capelos (University of Birmingham, UK), Stavroula Chrona (King's College London, UK), Mikko Salmela (University of Helsinki, Finland / University of Copenhagen, Denmark), and Cristiano Bee (Oxford Brookes University, UK).

(C) 2021 by the authors; licensee Cogitatio (Lisbon, Portugal). This article is licensed under a Creative Commons Attribution 4.0 International License (CC BY).

\section{Introduction}

The success of radical-right populist parties (RRP) across many Western democracies has created considerable interest among political scientists about the factors that have driven this support (e.g., Arzheimer \& Berning, 2019; Gidron \& Hall, 2017; Rydgren, 2008). Initially, most studies focused on short-term explanations for this support, such as economic, cultural, or status-threat perceptions, or preferences for specific policies (e.g., Rydgren, 2008). More recently, a growing number of researchers have been studying the psychological characteristics and basic values that underpin RRP support. This strand of research has highlighted the importance of fundamental traits, such as the Big Five personality traits or grandiose narcissism, and has shown that a considerable proportion of the population is, at least in principle, receptive to the appeal of RRPs (e.g., Ackermann et al., 2018; Aichholzer \& Zandonella, 2016; Bakker et al., 2016; Mayer et al., 2020). The focus on the psychological underpinnings of radical-right support, however, also raises a more fundamental question: Through which mechanisms are basic personality factors translated into political attitudes, and ultimately into behaviour? To address 
this question, we focus on three concepts that have been central to the public discussion of RRP support, but that have not yet been connected in the literature: narcissism, anger, and reactionary political orientation (RPO).

Previous studies found that the effect of personality traits on vote choice was mostly mediated by a set of more general attitudes or beliefs (e.g., Aichholzer \& Zandonella, 2016; Schimpf \& Schoen, 2017; Schoen \& Schumann, 2007). We follow this mediation logic and draw on Capelos and Katsanidou's (2018) concept of RPO to argue that focusing on such orientations helps clarify the mechanisms that connect psychological dynamics to political behaviour. By seeking to overturn the present social and political status quo for an (often naively) imagined idealised past, reactionary orientations form a co-occurring bundle of low political efficacy, a rejection of outsiders through xenophobia and anti-European sentiment, and low levels of political trust that closely match the discourse instrumentalised by populist parties and politicians (see also Nijs et al., 2020). We will argue that RPOs play an important mediating role in connecting personality traits to RRP support.

Existing studies have focused primarily on the Big Five personality traits as measures of personality, but they do not include other more fitting personality conceptions. Furthermore, the study of stable personality traits and RRP support limits our ability to account for short-term changes and the "political activation" of these traits. Using narcissism and placing RPOs at the centre of our theoretical model, however, helps us address both of these shortcomings. Using high-quality panel data from a mixed-mode access panel representative of the German population (GESIS panel), we analyse support for the Alternative für Deutschland (AfD) to argue that grandiose narcissism, particularly in its maladaptive form of narcissistic rivalry, is an important driver of RRP support, because it shares a close affinity with RPOs. Similarly, focusing on narcissism and RPOs also allows us to elaborate on the close relationship between anger and RRP support (Banks, 2016; Marcus et al., 2019; Rico et al., 2017). By integrating insights from personality psychology and the affective intelligence framework (Marcus, 2000), we demonstrate how important negative emotionality, especially anger, is for "activating" the RPOs of narcissistic individuals, and thus their support for RRPs.

\section{The Psychological Roots of RRP Support: Narcissism, Anger, and RPO}

On the individual level, existing explanations for RRP support have traditionally focused on socioeconomic factors and a subsequent backlash against cosmopolitan elites and immigration. Conceptualised as "losers of globalisation," RRP voters are less-educated, working class males with a greater risk of unemployment (Lengfeld, 2017; Oesch \& Rennwald, 2018) and are therefore more likely to be both economically and culturally threatened by increasingly open and less-traditional societies (for a discussion of the underpinnings of threat, see also the contribution by Ferrari, 2021, in this issue). But while debates are ongoing about whether RRP support is primarily driven by economic insecurity or driven simply by a cultural backlash against the perceived loss of privilege, the empirical support for the link between socioeconomic disadvantage and right-wing populism remains mixed at best (Knigge, 1998; Lengfeld, 2017; Rooduijn, 2017).

More recently, scholars have also begun to investigate how voters' underlying attitudes and values relate to their support for RRPs. Voters may be drawn to RRPs because they share their populist conception of democracy, or because they are psychologically predisposed towards supporting RRPs. This literature has identified a core set of populist attitudes, which is orthogonal to the traditional left-right party spectrum, and which focuses on the rejection of (political) elites and a homogenous conception of the body politic (Akkerman et al., 2014; Hawkins et al., 2018; Van Hauwaert \& Van Kessel, 2018).

However, voters may also be attracted by RRPs because of the parties' host ideology. We argue that there is a significant overlap between RPOs and RRP support. Specifically, the nativist and reactionary nostalgia at the core of RRPs host ideology (Betz \& Johnson, 2004; Steenvoorden \& Harteveld, 2018) closely mirrors the reactionary nostalgia of voters with strong RPOs (Capelos \& Katsanidou, 2018). As Capelos and Katsanidou (2018) emphasise, RPOs form voters' core political orientation, particularly their nostalgia for an idealised and homogenised past. In this, they are more than the sum of their individual parts; they are "complex clusters of resentful affective experiences" (Capelos \& Katsanidou, 2018 , p. 1284) that combine a desire to return to an idealised past with a resentful reaction towards the present. In addition, the contents of this conglomerate of backward-gazing values to an idealised past and a resentful affectivity towards what is new is also affected by the supply side of politics and a country-specific context (Capelos \& Katsanidou, 2018). For further discussion of the concept, see Salmela and Capelos (2021) in this issue. Thus, references to a strong state and a strong leader might not, in all countries, be connected to a wish to return to the past, but in others-such as Germany-they are closely linked with the Third Reich (e.g., Arzheimer \& Berning, 2019).

Following this theoretical insight, we argue that taking RPOs seriously can go a long way towards clarifying the mechanisms that connect voters' basic psychological makeup with their support for RRPs.

\subsection{RRP Support and Personality Structures: The Importance of Narcissism}

In recent years, a growing body of research has identified a close relationship between basic personality traits and support for RRPs. In this approach, support for RRPs 
is not simply an expression of temporary social or economic concerns, but rather a reflection of a more fundamental psychological disposition. A particular focus has been placed on the Big Five personality traits. Specifically, low levels of agreeableness and openness to experience, and sometimes a high level of conscientiousness and neuroticism, were found to be related to right-wing vote choice (Aichholzer \& Zandonella, 2016; Bakker et al., 2020; Schimpf \& Schoen, 2017). Moreover, ideological attitudes such as social-dominance orientation and rightwing authoritarianism have also exhibited strong associations with RRP support (Berning \& Ziller, 2017).

Placing voters' RPOs at the centre of our analysis, however, also sharpens our focus towards other less frequently studied personality traits such as the concept of grandiose narcissism (Raskin \& Hall, 1979). Grandiose narcissism usually describes a pattern of grandiosity, a need for admiration, and a lack of empathy for others (e.g., Campbell \& Miller, 2013). We focus on individual narcissism as a personality trait. Other studies, such as the one by de Zavala et al.(2009), rely on the concept of "collective narcissism," an emotionalised sub-facet of national identification alongside hostile reactions to in-group image threats which is not part of our study. Grandiose narcissism has been linked to a variety of negative outcomes related to psychological health (e.g., Campbell et al., 2002), but also to political ideology and prejudice (e.g., Cichocka et al., 2017). Regarding its relationship with the Big Five traits, narcissism is generally found to be closely related to agreeableness (negatively for rivalry) and extraversion (positively for admiration; e.g., Back et al., 2013). What makes the concept of narcissism so central to the study of RPOs, however, are the affective, cognitive, and behavioural dynamics that narcissists employ to maintain their grandiose self, particularly when their narcissism takes the maladaptive path of narcissistic rivalry. Specifically, Back et al. (2013) introduce two distinct domains of narcissism that have been validated by different studies (e.g., Leckelt et al., 2018; Rogoza, Żemojtel-Piotrowska, et al., 2016): narcissistic admiration and narcissistic rivalry. While narcissistic admiration refers to an adaptive pathway that uses assertive self-promotion and charmingness to strive for uniqueness, the maladaptive path of narcissistic rivalry protects the grandiose self through aggressiveness by striving for supremacy and by devaluating others.

It is this maladaptive path that is particularly salient for the study of RPOs and RRP support. To dismiss perceived threats to the ego, those with high levels of narcissistic rivalry will focus on controlling others and their environment to maintain the grandiose self (e.g., Rogoza, Żemojtel-Piotrowska, et al., 2016). Individuals with high narcissistic rivalry will thus respond to both real and imagined status threats with an aggressive devaluation of others, particularly of other social outgroups (e.g., Back et al., 2013). This in turn increases the appeal of RRPs. Indeed, a recent study by Mayer et al. (2020) finds a strong relationship between narcissistic rivalry and support for RRPs. Moreover, this relationship is mediated especially through anti-immigrant sentiment (AIS). With regard to values, previous studies have found a negative relationship between the high-order value conservation and narcissism but have failed to include items for the narcissistic rivalry dimension (e.g., Rogoza \& Cieciuch, 2020; Rogoza, Żemojtel-Piotrowska, et al., 2016). In contrast, Mayer et al. (2020) show a strong link between narcissistic rivalry and right-wing authoritarianism, a basic attitudinal belief system that strongly supports traditions and stability (Altemeyer, 1998).

We argue that the maladaptive responses associated with narcissistic rivalry should also be associated with an increase in more conservative and reactionary values. As discussed, rival narcissists protect their grandiose self through an aggressive elevation of their own identity vis-à-vis others, and through an attempt to assert supremacy over them. The rejection of immigrants is one such path. However, we argue that rival narcissists will also be drawn to the reactionary nostalgia at the core of RPOs, since the "nostalgic accounts of pride and feeling of strength" (Capelos \& Katsanidou, 2018, p. 1276) are inexorably linked to a sense of "national greatness and economic supremacy" (Capelos \& Katsanidou, 2018, p. 1284). The "idealised past" conjured up through RPOs is one of strong traditions, stability, and a strong state, all of which serve to protect the unquestioned supremacy of the in-group, and by extension, the rival narcissists.

To summarise, we hypothesise that high levels of narcissistic rivalry increase support for RRPs (Hypothesis 1). However, we expect that this effect will be mediated by RPOs (Hypothesis 2). Specifically, individuals with high levels of narcissistic rivalry will have higher levels of RPOs. Higher levels of RPOs thus increase support for RRPs.

\subsection{Anger and the Importance of Emotions}

Taking RPOs seriously also highlights an arguably more transient, but no less important, factor driving RRP support: voters' emotions. Scholars have increasingly recognised the importance that emotions play in understanding political behaviour in general (Marcus, 2000); negative emotions are central to explaining support for RRPs (Banks, 2016; Marcus et al., 2019; Vasilopoulos \& Lachat, 2018). Anger and resentment appear to be especially important for RRP attitudes and support (e.g., Rico et al., 2017). Indeed, the notion of the Wutbürger or the "angry white men" (Ford \& Goodwin, 2010)-citizens whose (excessive) anger drives them to reject "politics as usual" - has become a common trope for the description of reactionary politics and RRP voters.

Why is anger so inexorably linked with RRP support? Of course, anger may simply be part of the "political style" of populist parties (Moffitt \& Tormey, 2014) and the "resentful affectivity" (Capelos \& Katsanidou, 2018, p. 1274) associated with RPOs. (For another study on the concept of resentful affectivity, see the contribution by 
Celis et al., 2021, on this issue.) However, voters' emotions are not only a direct explanatory factor for RRP support, they also clarify the mechanisms that connect personality traits such as narcissistic rivalry, RPOs, and RRP support. Specifically, we make two related arguments. First, we follow insights from the affective intelligence literature (Marcus et al., 2019) to argue that the relationship between anger and RRP support is deeper, driven by the cognitive mechanisms associated with high levels of anger. Second, we emphasise the close link between anger and narcissism in general, and narcissistic rivalry in particular. Narcissistic individuals do not only experience anger more frequently, they also channel and express this anger differently.

The close relationship between anger and RRPs reflects a more general overlap between the cognitive effects of anger and the affective and attitudinal orientations of reactionary political values and RRP support. Affective intelligence theory has shown that anger is associated with habitual cognition and a reliance on established patterns of thought and behaviour. Because anger is focused on dealing with threats (Vasilopoulos et al., 2019) and rendering social judgement for violations of social norms (Petersen, 2010), angry individuals are more likely to assign blame and responsibility (Lerner \& Keltner, 2001; Lerner \& Tiedens, 2006). Anger thus links closely to several key components of the reactionary core of RRPs. Most fundamentally, anger not only increases the perceived responsibility of existing political elites but it also motivates voters to punish them (Lerner \& Tiedens, 2006; Milburn et al., 2014), creating a close affinity with the rejection of the political status quo that is core to RRPs. Moreover, anger is also linked to reactionary attitudes such as nativism and authoritarianism commonly associated with RRPs (Dunn, 2015; Van Hauwaert \& Van Kessel, 2018). Finally, the reduced depth of processing associated with anger also increases reliance on ethnocentrism and perceptions of groupthreat in particular (Banks, 2016).

Moreover, the cognitive dynamics associated with anger form the "connective tissue" that connects narcissism to RPOs, and ultimately to political behaviour such as RRP support. This connection happens in two distinct but related ways. First, personality traits structure emotional responses and thus also the frequency and strength of those responses. Anger, for example, seems to be at the emotional heart of narcissism, and the link between narcissism and anger has been a core component of our understanding of narcissism, both in their early psychoanalytic origins and in more contemporary studies in social psychology (Czarna et al., 2018; Sauls \& Zeigler-Hill, 2020). Narcissists experience anger at a consistently higher rate than non-narcissists (Czarna et al., 2018), and rival narcissists especially appear to have a more difficult time regulating negative emotions (Cheshure et al., 2020) such as anger (Krizan \& Johar, 2015). At least some narcissists may therefore have higher levels of trait anger, which in turn renders them more susceptible to the appeal of RPOs and more likely to support RRPs.

More importantly, however, narcissism also impacts the ways in which anger is triggered, channelled, and expressed. As outlined above, rival narcissists more frequently channel their anger in an aggressive assertion of dominance and superiority to counteract ego threats (Czarna et al., 2018). In other words, narcissists may not only experience anger more frequently, but they also act differently when they get angry. The habitual pattern triggered for a person with a high level of rival narcissism is more likely to evolve around social dominance and hierarchy and the devaluation of others, thus creating a much closer affinity to RPOs and RRPs. We thus hypothesise that anger activates the relationships between (rival) narcissism, RPOs, and RRP support (Hypothesis 3), either because anger leads to rival narcissists having higher levels of RPOs, or because anger makes RPOs more salient for the support of RRPs (Hypotheses 3a and $3 \mathrm{~b}$ respectively).

Figure 1 summarises our argument and our hypotheses. We contend that RPOs are an important factor in the study of RRP support, not only because RPOs directly explain subsequent vote choice, but also because they are an important path on which personality traits, particularly narcissistic rivalry, can be made politically salient and actionable. Moreover, we highlight the important role that anger plays in connecting these relationships. While anger in general shares some overlap with RPOs, it is especially important for the activation of rival narcissism, both by increasing the appeal of RPOs and in the ways in which these orientations influence the subsequent appeal of RRPs.

\section{Data and Methods}

Our study draws on several waves of the GESIS panel (Bosnjak et al., 2017; GESIS, 2017), a bi-monthly mixedmode access panel representative of the German population, with a response rate of over $90 \%$. The initial recruitment of the respondents was carried out in February 2014 and replacement waves were conducted in 2016 and 2018. The data we used was mostly collected in 2017 (waves $E^{*}$ ) and 2018 (waves GA). Panellists who have missing values for any of the variables we are interested in are excluded from the analyses, hence our analyses are based on $\mathrm{N}=2,525$ individuals for the regression analysis and $\mathrm{N}=1,901$ for the mediation analysis. We pooled several waves for our measures (see Supplementary File, Table A1, for the descriptive statistics, the wording of questions, and specific wave references for all variables).

Our main dependent variable is RRP support, captured here through electoral support for the rightwing populist AfD. Specifically, respondents were asked directly after the general election of 2017 for which party they had voted with their second vote. We coded all respondents who named the AfD with 1 and coded 0 for respondents who took part in the election but who 


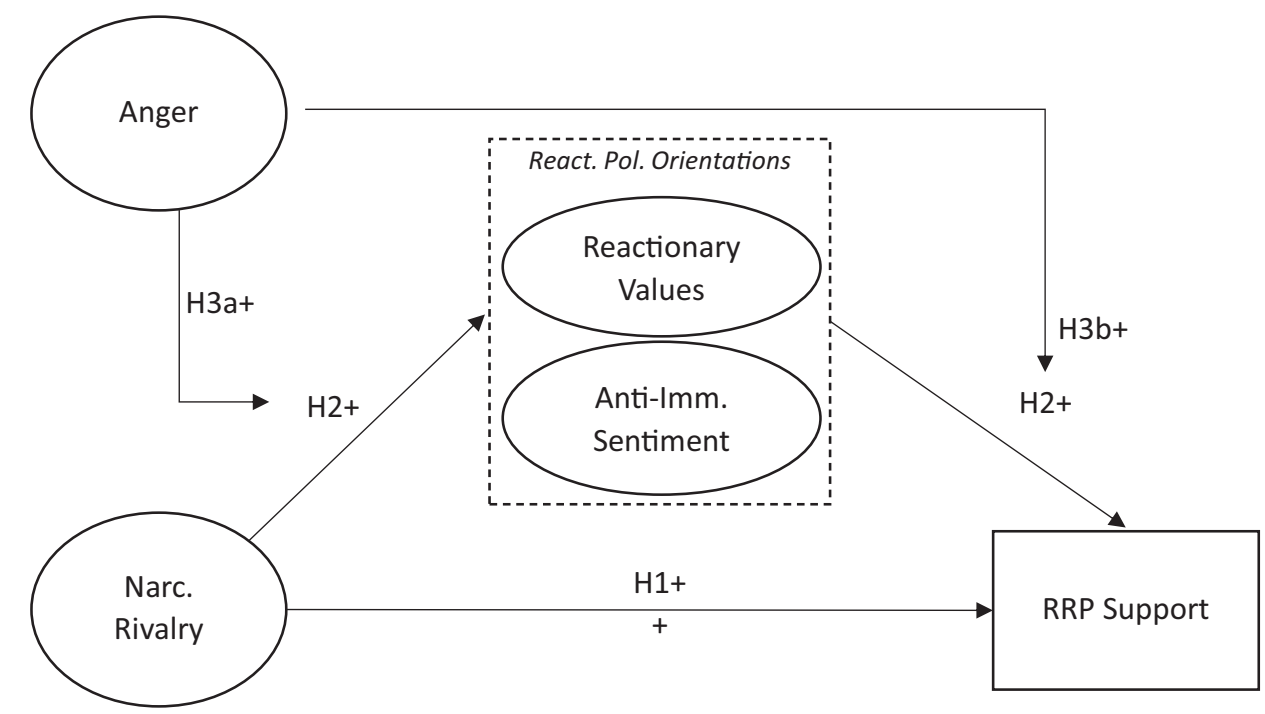

Figure 1. Theoretical model of the relationship between narcissistic rivalry, anger, RPOs and RRP support.

voted differently with their second vote. Our analyses thus exclude all non-voters ( $10 \%$ of all cases; $N=394$ ). The result was that $9.9 \%$ of the respondents indicated that they had voted for the AfD. This is lower than the official second vote count of $12.6 \%$, a phenomenon wellknown in research (e.g., Mayer et al., 2020).

To measure narcissism, we used a validated short scale of the Narcissistic Admiration and Rivalry Questionnaire (NARQ, Back et al., 2013), which measures each dimension with three items such as "I earned being viewed as a great personality" (for narcissistic admiration), and "I want my opponents to fail" and "Most people are losers" (for narcissistic rivalry; e.g., Paulhus et al., 2004). The answer options ranged from 1 (does not apply at all) to 6 (fully applies).

We operationalised RPOs based on two different but related concepts: reactionary value orientation (focused on the past) and AIS (as an affective measure of resentment towards newcomers). To capture reactionary value orientations, respondents were asked to what extent they are similar to (a) citizens who seek to preserve traditional values and beliefs (value facet tradition, Schwartz et al., 2012), and (b) citizens who prefer a strong state (value facet security/societal, Schwartz et al., 2012). The options ranged from 1 (not at all similar) to 6 (very similar). Both values are part of the higher order value "Conservation" (Schwartz et al., 2012). For the measurement of affective resentment towards newcomers, we used four items to measure AIS that asked for feelings towards Muslims, foreigners, refugees, and Sinti and Roma in Germany ( 1 for very positive to 5 for very negative; $\alpha=0.83$ ). To measure generalised negative emotions-fear and anger specifically-respondents were asked how frequently they had felt afraid or annoyed in the last four weeks ( 0 for not at all to 10 very often). It is important to note that this measurement may capture both a temporary increase in these emotions or a more general disposition towards them. However, both trait and state anger shape judgements and cognition in similar ways, and higher levels of state anger are also linked to greater incidence of state anger (Deffenbacher et al., 1996). So, while these measures cannot disentangle generalised trait and state emotions, the overarching relationship to narcissism, RPOs, and RRP support should still fall in line with our theoretical priors.

To maintain comparability with standard models of RRP vote choice, all models control for standard sociodemographic factors such as gender, educational level, East or West German origin, age, as well as labour market status through a dummy variable for regular employment (full time or part time; e.g., Arzheimer \& Berning, 2019) and left-right self-placement. In addition, all logistic regression models include political attitudes that in previous studies were found to have a substantial effect on RRP vote choice: internal and external efficacy (recoded so that higher values indicate higher efficacy), satisfaction with democracy, and satisfaction with their financial situation.

For the initial results, we estimated logistic regression models with robust standard errors for vote choice. For these estimates, we used mean indices for narcissism, reactionary political values, and AIS. To test the model outlined in Figure 1 directly, we then used structural equation modelling (SEM) to estimate a moderated mediation model which can simultaneously estimate all the paths outlined in Figure 1. This model aims to estimate both the direct and indirect effect of narcissistic rivalry through increases in reactionary political values on RRP vote choice. Moreover, we conducted the analysis for angry and non-angry individuals simultaneously (anger was defined as individuals being above or below the median anger score in the sample) to estimate the moderating effect that anger may have on both the direct and indirect paths. For these analyses, we included narcissism, reactionary political values, and AIS as latent variables. All mediated moderation models 
were estimated through SEMs using lavaan (Rosseel, 2012) with diagonally weighted least square (DWLS) estimation. We recoded all independent variables to a range from 0 to 1 so that all analyses could compare non-standardised estimates between models.

We are aware of the many restrictions of using moderated mediation analysis with cross-sectional data instead of panel data, as cross-sectional data analyses, for example, sometimes cannot reveal the real longitudinal mediation process (for an overview, see e.g., O'Laughlin et al., 2018; Rohrer et al., 2021). However, we were not able to use panel data for the variables of interest as they were not measured regularly enough. In such cases, especially in studies between personality traits and vote choice, relying on cross-sectional data is an established approach with the clear need to carefully discuss one's assumptions and to proceed with caution (e.g., Wang, 2016). It is thus necessary to rule out possible confounders of the independent, mediator, and dependent variable, as well as to discuss the possibility of reverse causality (Rohrer et al., 2021). In addition, our treatment should be independent from the mediator (Imai et al., 2011). We controlled for several variables that might have affected our three variables of interest-as discussed in the previous paragraph-to account for the first assumption. Next, reverse causality does not seem to be plausible for the path from narcissistic rivalry to RPO, as personality traits are supposed to be very stable (e.g., Back et al., 2013; Wang, 2016). We also assumed that the two facets of RPO-reactionary values and AISare longstanding belief systems that are causally placed at the same level, but we agree that this could be debatable. For the path between RPO and vote choice, we assumed, based on previous studies, that vote choice is less stable than values, and thus that a path from RPO to vote choice-and not the other way around-is plausible (Caprara et al., 2006).

To facilitate transparency and replicability, all data cleaning and analysis code has been uploaded to the OSF.io repository (Mayer \& Nguyen, 2021).

\section{Results}

\subsection{RPOs Mediate the Effect of Narcissism and Negative Emotions on RRP Support}

We have hypothesised that narcissistic rivalry increases RRP support, but that this support may be mediated through reactionary political values. To test these hypotheses empirically, we begin with a stepwise regression analysis that shows how our core variables of interest behave in relation to vote choice for the AfD (see Table 1), and how this relationship changes when additional variables are included. As expected, we find stronger evidence for Hypothesis 2 than for Hypothesis 1. While we initially find a direct relationship between narcissistic rivalry and RRP support in models $\mathrm{MO}$ and $M 1$, this relationship becomes non-significant once we include controls for RPOs. This does not change in model M3, where we include additional controls that have been found to explain RRP support. The effect of anger appears to be similarly mediated. Although anger remains significant in model $\mathrm{M} 2$, including the full set of controls similarly renders it non-significant. In short, the results in Table 1 give a strong indication that the effects of narcissism are mediated by RPOs, and that negative emotions such as anger and resentment play a similarly contingent role in driving RRP support. When including the Big Five personality traits (based on the BFI-10), rivalry is only significant in model $\mathrm{MO}$ at the $10 \%$ level. However, none of the Big Five traits has a significant relationship in model M3. Furthermore, RPOs are important drivers of RRP support in model M3, especially AIS.

\subsection{Anger Makes Narcissism and RPOs Politically Salient}

While the results in Table 1 show some support for Hypothesis 2, untangling the relationship shown in Figure 1 between narcissistic rivalry, anger, RPOs, and RRP support requires a modelling approach that allows us to capture both the mediating role of RPOs and the moderating role of anger, while also controlling for the full set of independent variables outlined in Table 1. We therefore employed a mediated moderation SEM to simultaneously estimate all paths shown in Figure 1 and estimated the extent to which narcissistic rivalry is linked to RRP support either directly (Hypothesis 1) or indirectly through RPOs (Hypothesis 2), and to what extent these relationships may be moderated by respondents' level of anger (Hypothesis 3).

Table 2 summarises the results of our main mediated moderation analysis (for the full model see SI, Table A3) and strongly supports Hypothesis 2. Reactionary political values fully mediate the effect of narcissistic rivalry on RRP support. Indeed, as in Table 1, we find no significant direct effect once potential mediating relationships are considered. Moreover, we also find support for Hypothesis 3. Anger is a necessary condition of the relationship between narcissism and RRP support. The total effect of narcissistic rivalry is non-significant in the low anger condition but becomes significant in the high anger condition. However, this relationship is mediated through RPOs. The direct effect of narcissistic rivalry on RRP support is not statistically significant in either condition.

Moreover, these relationships appear to be robust with the inclusion of other personality variables, such as the Big Five personality traits or measures of narcissistic admiration and generalised anxiety (see Supplementary File, Tables A4 and A5). The same is true for the inclusion of financial satisfaction (Supplementary File, Table A6).

However, the SEM model also lets us disentangle these relationships further. Table 3 disaggregates the mediated relationships into the two subcomponents of RPOs we have identified: reactionary political values and AIS. Doing so demonstrates that, while the relationship 
Table 1. Stepwise logistic regression models on RRP support, average marginal effects.

\begin{tabular}{lcccc}
\hline & M0 Narcissism baseline & M1 + Emotions & M2 + RPOs & M3 Full model \\
\hline Narcissistic admiration & -0.03 & -0.03 & 0.00 & -0.00 \\
& $(0.04)$ & $(0.04)$ & $(0.04)$ & $(0.03)$ \\
Narcissistic rivalry & $0.14^{* *}$ & $0.13^{* *}$ & 0.00 & -0.01 \\
& $(0.05)$ & $(0.05)$ & $(0.05)$ & $(0.04)$ \\
Emotion: Fear & & -0.06 & -0.04 & -0.03 \\
& & $(0.04)$ & $(0.03)$ & $(0.03)$ \\
Emotion: Anger & & $0.10^{* * *}$ & 0.04 & 0.01 \\
& & $(0.03)$ & $(0.02)$ & $(0.02)$ \\
Reactionary Orientations & & & \\
Reactionary political values & & & $0.19^{* * *}$ & $0.12^{* * *}$ \\
& & & $(0.04)$ & $(0.03)$ \\
AIS index & & & $0.53^{* * *}$ & $0.27^{* * *}$
\end{tabular}

Common explanatory variables

for RRP vote choice

Internal political efficacy

0.04

$(0.02)$

External political efficacy

$-0.11^{* * *}$

Satisfaction: Democracy

$-0.23 * * *$

$(0.02)$

Satisfaction: Financial situation

$-0.02$

$(0.02)$

Left-right self-placement

$0.18^{* * *}$

$(0.02)$

0.00

Occupational status: Full/part time

$(0.01)$

Socio-demographic controls

Age in years

Education (ref. cat: middle)

Low

High

Origin: East Germany

Gender: Male

$\mathrm{N}$

Nagelkerke's Pseudo- $\mathrm{R}^{2}$

AIC

BIC
$-0.00$

$(0.00)$

0.03

(0.02)

0.00

$(0.00)$

$-0.07 * * *$

$(0.01)$

$0.06 * * *$

$(0.01)$

$0.04 * *$

$(0.01)$

2,552

0.06

1402

1449
0.03

(0.02)

$-0.06 * * *$

(0.01)

$0.06^{* * *}$

(0.01)

$0.04^{* * *}$

(0.01)

2,552

0.07

1392

1451
$-0.00$

(0.00)

$-0.00$

$(0.00)$

0.02

(0.02)

$-0.02$

(0.01)

0.02 *

$(0.01)$

0.02 *

(0.01)

$(0.01)$

2,552

0.42

890

995

Notes: Standard errors in parentheses; sample weight $(\mathrm{pw}=\mathrm{z000011a)}$ and cluster robust SE used; all independent variables recoded to the range of $0-1 ; * * * p<0.001, * * p<0.01 ; * p<0.05$. 
Table 2. Summary of mediated moderation models: General overview.

\begin{tabular}{llccc}
\hline & \multicolumn{3}{c}{ Effects on RRP support } \\
\cline { 2 - 5 } & Anger & Direct & Total indirect via RPOs & Total \\
\hline Narcissistic rivalry & Low & -0.477 & $1.359 * * *$ & 0.883 \\
& & $(p=0.598)$ & $(p=0.001)$ & $(p=0.312)$ \\
& High & 0.226 & $1.665^{* * *}$ & $1.892^{*}$ \\
& & $(p=0.774)$ & $(p=0.000)$ & $(p=0.016)$ \\
\hline
\end{tabular}

Notes: ${ }^{* *} p<0.001,{ }^{* *} p<0.01 * p<0.05 ; \mathrm{N}=1,901, \chi^{2}=652.188, \mathrm{DF}=90, \mathrm{RMSEA}=0.0542, \mathrm{CFI}=0.907$; all coefficients are standardised estimates.

Table 3. Mediated moderation models: Detailed overview.

\begin{tabular}{llcrr}
\hline Effect on RRP support mediated by... & Anger & Effect size & Std. Error & p-value \\
\hline AIS & Low & 1.533 & 0.263 & $<0.001$ \\
& High & 1.035 & 0.334 & $<0.001$ \\
Reactionary political values & Low & -0.174 & 0.171 & 0.310 \\
& High & 0.630 & 0.238 & 0.008 \\
\hline
\end{tabular}

Notes: $\mathrm{N}=1,901 ; \chi^{2}=652.188, \mathrm{DF}=90, \mathrm{RMSEA}=0.0542, \mathrm{CFI}=0.907 ;$ all coefficients are standardised estimates.

between narcissism, AIS and RRP support can be found in both low and high anger conditions, reactionary political values are only linked to RPOs in high anger conditions.

To test Hypotheses $3 \mathrm{a}$ and $3 \mathrm{~b}$ specifically, Figure 2 disaggregates this relationship further. Specifically, Figure 2 shows how narcissistic rivalry is linked to reactionary values and to AIS, and how these are in turn related to RRP support for both the low and high anger conditions. Disaggregating the paths further helps to suggest a particular mechanism in play. Most paths are consistent in both the low and the high anger conditions; only the path between narcissistic rivalry and reactionary political values is statistically different between the low and high anger conditions ( $p=0.001)$. In other words, some aspects of RPOs are independent of respondent anger. Rival narcissism always correlates with higher AIS, which in turn is associated with a higher probability to vote for the AfD. However, anger seems to play a central role in "activating" the value dimension of RPOs, and thus RRP support. While voters with reactionary political values always show higher support for RRPs, narcissistic rivalry only becomes associated with reactionary political values when respondents are also at higher levels of anger. In other words, the results suggest that it is anger that makes narcissistic rivalry politically salient. In summary, our results clearly support our theoretical priors: 1) that RPO mediates the relationship between narcissistic rivalry and RRP support, and 2) that anger, even when it is generalised, is a crucial component of these relationships.

\section{Concluding Remarks and Perspectives}

Understanding the mechanisms behind RRP support allows society to take a better stance against the rise of such parties that often deeply divide society. Previous research on the psychological roots of RRP support found some personality traits such as narcissistic rivalry,
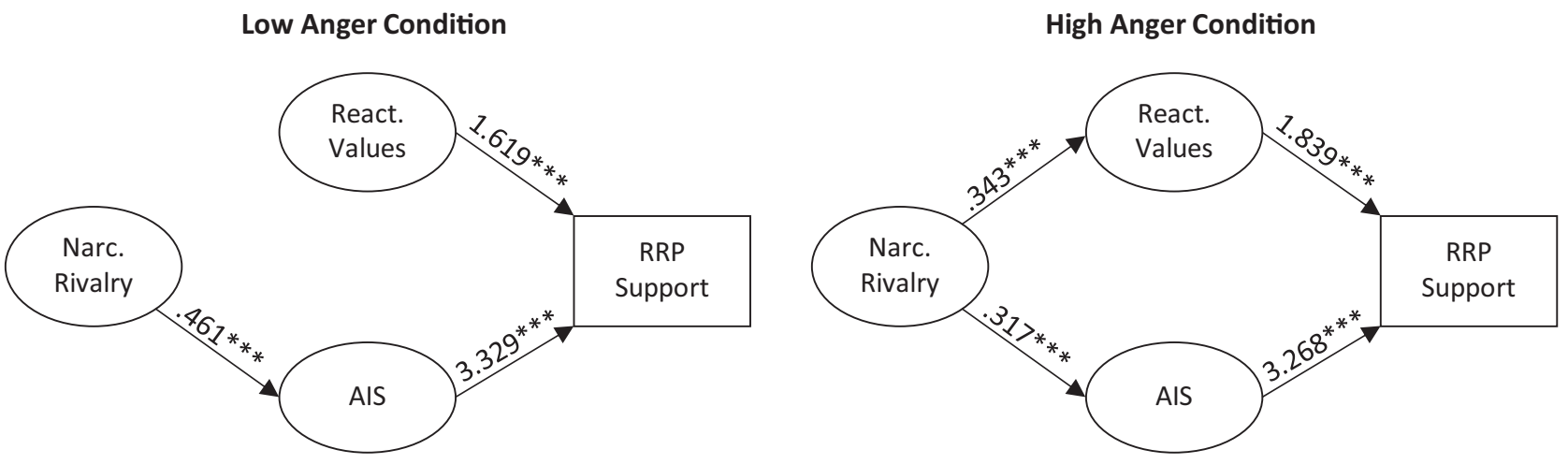

Figure 2. Mediation between narcissistic rivalry and RRP support for low and high anger conditions (only significant paths are displayed). 
and emotions such as anger, to be strongly connected. In addition, a more general, backward-looking, reactionary political perspective also fosters RRP. However, existing studies have not considered the dynamic interplay between these different factors, thus leaving the mechanisms understudied. This article has attempted to address that gap.

We find that RPOs, such as value orientations for supporting a strong state and traditional ways, as well as AIS, play an important role in driving RRP support, even when controlling for other factors known from the literature. Moreover, focusing on RPOs also clarifies the relationships that connect personality structure, emotions, and RRP support. The effect of narcissistic rivalry on RRP support, for example, is mediated through both AIS (replicating the findings of Mayer et al., 2020) and a value orientation that focuses on traditional values and a strong state. However, this second relationship needs to be "activated" by negative emotions: Narcissism is only associated with more reactionary political values when respondents are angry.

Our article thus makes an important contribution to several different studies. Most directly, our article adds to the study of RRP support, highlighting once more that psychological factors such as personality structure and emotions are crucial components of RRP support, although their effect is entirely mediated through intermediate political orientations. However, our article also explores the mechanisms that connect "basic" psychological factors to political behaviour more closely. When focusing on the role that emotions play, we find that generalised anger is an important component for the association between narcissistic rivalry and RPOs, and ultimately for RRP support. As anger can also be triggered by current and past events, it can thus be one of the missing pieces of the puzzle of why some people with a specific predisposition support an RRP. This shows the importance of interdisciplinary research between psychology and political science.

Our study is not without limitations. Our results are based on the German case and only focus on one year (2017). It is thus to be seen whether the results are time-and place-invariant. However, the AfD is now considered a rather typical case of an RRP (e.g., Arzheimer \& Berning, 2019), and the immigrant influx of 2015 was already two years past when the data of our study were obtained, thus making it more likely that our results are not unique to Germany. In addition, we are not able to observe how anger, narcissism, and RPOs interact in a longitudinal or experimental context. Future research thus needs to expand on our dynamic perspective and empirically test not only how stable these patterns are, but also whether these mechanisms are actually causal, as our results are based on cross-sectional data. Nevertheless, our results clearly suggest how complex the relationship can be between personality, value orientations and political behaviour.

\section{Acknowledgments}

Both authors contributed equally and share first authorship. We thank the anonymous reviewers and the editors for helpful comments. We also thank Jonas Köhler for research assistance and John Revington for language editing.

\section{Conflict of Interests}

The authors declare no conflict of interests.

\section{Supplementary Material}

Supplementary material for this article is available online in the format provided by the author (unedited).

\section{References}

Ackermann, K., Zampieri, E., \& Freitag, M. (2018). Personality and voting for a right-wing populist partyEvidence from Switzerland. Swiss Political Science Review, 24(4), 545-564. https://doi.org/10.1111/ spsr.12330

Aichholzer, J., \& Zandonella, M. (2016). Psychological bases of support for radical right parties. Personality and Individual Differences, 96, 185-190. https:// doi.org/10.1016/j.paid.2016.02.072

Akkerman, A., Mudde, C., \& Zaslove, A. (2014). How populist are the people? Measuring populist attitudes in voters. Comparative Political Studies, 47(9), 1324-1353. https://doi.org/10.1177/001041401351 2600

Altemeyer, R. A. (1998). The other "authoritarian personality." In M. P. Zanna (Ed.), Advances in experimental social psychology (pp. 47-91). Academic Press.

Arzheimer, K., \& Berning, C. C. (2019). How the Alternative for Germany (AfD) and their voters veered to the radical right, 2013-2017. Electoral Studies, 60, Article 102040. https://doi.org/10.1016/j.electstud. 2019.04.004

Back, M. D., Küfner, A. C. P., Dufner, M., Gerlach, T. M., Rauthmann, J. F., \& Denissen, J. J. A. (2013). Narcissistic admiration and rivalry: Disentangling the bright and dark sides of narcissism. Journal of Personality and Social Psychology, 105(6), 1013-1037. https:// doi.org/10.1037/a0034431

Bakker, B., Rooduijn, M., \& Schumacher, G. (2016). The psychological roots of populist voting: Evidence from the United States, the Netherlands and Germany. European Journal of Political Research, 55, 302-320. https://doi.org/10.1111/1475-6765.12121

Bakker, B., Schumacher, G., \& Rooduijn, M. (2020). The populist appeal: Personality and anti-establishment communication. The Journal of Politics. Advance online publication. https://doi.org/10.1086/710014

Banks, A. J. (2016). Are group cues necessary? How anger makes ethnocentrism among whites a stronger 
predictor of racial and immigration policy opinions. Political Behavior, 38(3), 635-657. https://doi.org/ 10.1007/s11109-016-9330-3

Berning, C. C., \& Ziller, C. (2017). Social trust and radical right-wing populist party preferences. Acta Politica, 52(2), 198-217.

Betz, H.-G., \& Johnson, C. (2004). Against the currentStemming the tide: The nostalgic ideology of the contemporary radical populist right. Journal of Political Ideologies, 9(3), 311-327.

Bosnjak, M., Dannwolf, T., Enderle, T., Schauer, I., Struminskaya, B., Tanner, A., \& Weyandt, K. W. (2017). Establishing an open probability-based mixed-mode panel of the general population in Germany: The GESIS panel. Social Science Computer Review, 36(1), 103-115. https://doi.org/10.1177/ 0894439317697949

Campbell, W. K., \& Miller, J. D. (2013). Narcissistic personality disorder and the five-factor model: Delineating narcissistic personality disorder, grandiose narcissism, and vulnerable narcissism. In T. A. Widiger \& P. T. Costa Jr. (Eds.), Personality disorders and the five-factor model of personality (pp. 133-145). APA. https://doi.org/10.1037/13939-009

Campbell, W. K., Foster, C. A., \& Finkel, E. J. (2002). Does self-love lead to love for others? A story of narcissistic game playing. Journal of Personality and Social Psychology, 83(2), 340-354. https://doi.org/ 10.1037/0022-3514.83.2.340

Capelos, T., \& Katsanidou, A. (2018). Reactionary politics: Explaining the psychological roots of anti preferences in European integration and immigration debates. Political Psychology, 39(6), 1271-1288. https://doi. org/10.1111/pops.12540

Caprara, G. V., Schwartz, S., Capanna, C., Vecchione, M., \& Barbaranelli, C. (2006). Personality and politics: Values, traits, and political choice. Political Psychology, 27(1), 1-28. https://doi.org/10.1111/ j.1467-9221.2006.00447.x

Celis, K., Knops, L., Van Ingelgom, V., \& Verhaegen, S. (2021). Resentment and coping with the democratic dilemma. Politics and Governance, 9(3), 237-247.

Cheshure, A., Zeigler-Hill, V., Sauls, D., Vrabel, J. K., \& Lehtman, M. J. (2020). Narcissism and emotion dysregulation: Narcissistic admiration and narcissistic rivalry have divergent associations with emotion regulation difficulties. Personality and Individual Differences, 154, Article 109679. https://doi.org/10.1016/ j.paid.2019.109679

Cichocka, A., Dhont, K., \& Makwana, A. P. (2017). On self-love and outgroup hate: Opposite effects of narcissism on prejudice via social dominance orientation and right-wing authoritarianism. European Journal of Personality, 31(4), 366-384. https://doi.org/ 10.1002/per.2114

Czarna, A. Z., Zajenkowski, M., \& Dufner, M. (2018). How does it feel to be a narcissist? Narcissism and emotions. In A. D. Hermann, A. B. Brunell, \& J. D. Fos- ter (Eds.), Handbook of trait narcissism (pp. 255-263). Springer. https://link.springer.com/chapter/ 10.1007/978-3-319-92171-6_27

de Zavala, A. G., Cichocka, A., Eidelson, R., \& Jayawickreme, N. (2009). Collective narcissism and its social consequences. Journal of Personality and Social Psychology, 97(6), 1074-1096. https://doi.org/10.1037/ a0016904

Deffenbacher, J. L., Oetting, E. R., Thwaites, G. A., Lynch, R. S., Baker, D. A., Stark, R. S., Thacker, S., \& EiswerthCox, L. (1996). State-trait anger theory and the utility of the trait anger scale. Journal of Counseling Psychology, 43(2), 131-148. https://doi.org/10.1037/00220167.43.2.131

Dunn, K. (2015). Preference for radical right-wing populist parties among exclusive-nationalists and authoritarians. Party Politics, 21(3), 367-380. https://doi. org/10.1177/1354068812472587

Ferrari, D. (2021). Perceptions, resentment, economic distress, and support for right-wing populist parties in Europe. Politics and Governance, 9(3), 274-287.

Ford, R., \& Goodwin, M. J. (2010). Angry white men: Individual and contextual predictors of support for the British national party. Political Studies, 58(1), 1-25. https://doi.org/10.1111/j.1467-9248.2009.00829.x

GESIS. (2017). GESIS panel: Standard edition [Data set]. GESIS. https://doi.org/10.4232/1.13210

Gidron, N., \& Hall, P. A. (2017). The politics of social status: Economic and cultural roots of the populist right. The British Journal of Sociology, 68(S1), S57-S84.

Hawkins, K. A., Kaltwasser, C. R., \& Andreadis, I. (2018). The activation of populist attitudes. Government and Opposition, 55(2), 283-307. https://doi.org/ 10.1017/gov.2018.23

Imai, K., Keele, L., Tingley, D., \& Yamamoto, T. (2011). Unpacking the black box of causality: Learning about causal mechanisms from experimental and observational studies. American Political Science Review, 105(4), 765-789. https://doi.org/10.1017/ S0003055411000414

Knigge, P. (1998). The ecological correlates of right wing extremism in Western Europe. European Journal of Political Research, 34(2), 249-279.

Krizan, Z., \& Johar, O. (2015). Narcissistic rage revisited. Journal of Personality and Social Psychology, 108(5), 784-801. https://doi.org/10.1037/pspp0000013

Leckelt, M., Wetzel, E., Gerlach, T. M., Ackerman, R. A., Miller, J. D., Chopik, W. J., Penke, L., Geukes, K., Kufner, A. C. P., Hutteman, R., Richter, D., Renner, K.-H., Allroggen, M., Brecheen, C., Campell, W. K., Grossmann, I., \& Back, M. D. (2018). Validation of the narcissistic admiration and rivalry questionnaire short scale (NARQ-S) in convenience and representative samples. Psychological Assessment, 30(1), 86-96. https://doi.org/10.1037/pas0000433

Lengfeld, H. (2017). Die "Alternative für Deutschland": Eine Partei für Modernisierungsverlierer? [The Alter- 
native for Germany: A party for losers of modernization?] Kölner Zeitschrift für Soziologie und Sozialpsychologie, 69(2), 209-232. https://doi.org/10.1007/ s11577-017-0446-1

Lerner, J., \& Keltner, D. (2001). Fear, anger, and risk. Journal of Personality and Social Psychology, 81(1), 146-159.

Lerner, J., \& Tiedens, L. (2006). Portrait of the angry decision maker: How appraisal tendencies shape anger's influence on cognition. Journal of Behavioral Decision Making, 19(2), 115-137.

Marcus, G. E. (2000). Emotions in politics. Annual Review of Political Science, 3, 221-250. https://doi.org/ 10.1146/annurev.polisci.3.1.221

Marcus, G. E., Valentino, N. A., Vasilopoulos, P., \& Foucault, M. (2019). Applying the theory of affective intelligence to support for authoritarian policies and parties. Political Psychology, 40(S1), 109-139. https://doi.org/10.1111/pops.12571

Mayer, S. J., Berning, C. C., \& Johann, D. (2020). The two dimensions of narcissistic personality and support for the radical right: The role of right-wing authoritarianism, social dominance orientation and antiimmigrant sentiment. European Journal of Personality, 34(1), 60-76. https://doi.org/10.1002/per.2228

Mayer, S. J., \& Nguyen, C. G. (2021). Reactionary angry narcissists? Anger activates the link between narcissism \& radical right populist party support [Data set]. OSF. https://doi.org/10.17605/OSF.IO/BH4ZD

Milburn, M. A., Niwa, M., \& Patterson, M. D. (2014). Authoritarianism, anger, and hostile attribution bias: A test of affect displacement. Political Psychology, 35(2), 225-243. https://doi.org/10.1111/pops. 12061

Moffitt, B., \& Tormey, S. (2014). Rethinking populism: Politics, mediatisation and political style. Political Studies, 62(2), 381-397. https://doi.org/10.1111/14679248.12032

Nijs, T., Martinovic, B., Verkuyten, M., \& Sedikides, C. (2020). 'This country is OURS': The exclusionary potential of collective psychological ownership. The British Journal of Social Psychology, 60(1), 171-195. https://doi.org/10.1111/bjso.12386

Oesch, D., \& Rennwald, L. (2018). Electoral competition in Europe's new tripolar political space: Class voting for the left, centre-right and radical right. European Journal of Political Research, 57(4), 783-807. https:// doi.org/10.1111/1475-6765.12259

O'Laughlin, K. D., Martin, M. J., \& Ferrer, E. (2018). Cross-sectional analysis of longitudinal mediation processes. Multivariate Behavioral Research, 53(3), 375-402. https://doi.org/10.1080/00273171. 2018.1454822

Paulhus, D. L., Robins, R. W., Trzesniewski, K. H., \& Tracy, J. L. (2004). Two replicable suppressor situations in personality research. Multivariate Behavioral Research, 39(2), 303-328. https://doi.org/10.1207/ s15327906mbr3902_7
Petersen, M. B. (2010). Distinct emotions, distinct domains: Anger, anxiety and perceptions of intentionality. The Journal of Politics, 72(2), 357-365.

Raskin, R. N., \& Hall, C. S. (1979). A narcissistic personality inventory. Psychological Reports, 45(2), 590. https:// doi.org/10.2466/pr0.1979.45.2.590

Rico, G., Guinjoan, M., \& Anduiza, E. (2017). The emotional underpinnings of populism: How anger and fear affect populist attitudes. Swiss Political Science Review, 23(4), 444-461. https://doi.org/10.1111/ spsr.12261

Rogoza, R., \& Cieciuch, J. (2020). Dark Triad traits and their structure: An empirical approach. Current Psychology, 39(4), 1287-1302. https://doi.org/10.1007/ s12144-018-9834-6

Rogoza, R., Żemojtel-Piotrowska, M., Rogoza, M., Piotrowski, J., \& Wyszyńska, P. (2016). Narcissistic admiration and rivalry in the context of personality metatraits. Personality and Individual Differences, 102, 180-185. https://doi.org/10.1016/j.paid.2016. 07.003

Rohrer, J. M., Hünermund, P., Arslan, R. C., \& Elson, M. (2021). That's a lot to PROCESS! Pitfalls of Popular Path Models. PsyArXiv. https://doi.org/10.31234/osf. io/paeb7

Rooduijn, M. (2017). What unites the voter bases of populist parties? Comparing the electorates of 15 populist parties. European Political Science Review, 10(3), 351-368. https://doi.org/10.1017/ S1755773917000145

Rosseel, Y. (2012). lavaan: An R package for structural equation modeling. Journal of Statistical Software, 48(2). https://doi.org/10.18637/jss.v048.i02

Rydgren, J. (2008). Immigration sceptics, xenophobes or racists? Radical right-wing voting in six West European countries. European Journal of Political Research, 47(6), 737-765.

Salmela, M., \& Capelos, T. (2021). Ressentiment: A complex emotion or an emotional mechanism of psychic defences? Politics and Governance, 9(3), 191-203.

Sauls, D., \& Zeigler-Hill, V. (2020). Basic emotional systems and narcissistic personality features: What is the emotional core of narcissism? Personality and Individual Differences, 162, Article 110032. https:// doi.org/10.1016/j.paid.2020.110032

Schimpf, C., \& Schoen, H. (2017). On the psychological roots of populist voting: $A$ discussion of Bakker, Rooduijn, and Schumacher (2016). Unpublished manuscript.

Schoen, H., \& Schumann, S. (2007). Personality traits, partisan attitudes, and voting behavior. Evidence from Germany. Political Psychology, 28(4), 471-498. https://doi.org/10.1111/j.1467-9221.2007.00582.x

Schwartz, S. H., Cieciuch, J., Vecchione, M., Davidov, E., Fischer, R., Beierlein, C., Ramos, A., Verkasalo, M., Lonnqvist, J.-E., Demirutku, K., Dirilen-Gumus, O., \& Konty, M. (2012). Refining the theory of basic individual values. Journal of Personality and Social Psy- 
chology, 103(4), 663-688. https://doi.org/10.1037/ a0029393

Steenvoorden, E., \& Harteveld, E. (2018). The appeal of nostalgia: The influence of societal pessimism on support for populist radical right parties. West European Politics, 41(1), 28-52.

Van Hauwaert, S. M., \& Van Kessel, S. (2018). Beyond protest and discontent: A cross-national analysis of the effect of populist attitudes and issue positions on populist party support. European Journal of Political Research, 57(1), 68-92. https://doi.org/10.1111/ $1475-6765.12216$
Vasilopoulos, P., \& Lachat, R. (2018). Authoritarianism and political choice in France. Acta Politica, 53(4), 612-634. https://doi.org/10.1057/s41269-0170066-9

Vasilopoulos, P., Marcus, G. E., Valentino, N. A., \& Foucault, M. (2019). Fear, anger, and voting for the far right: Evidence from the November 13, 2015 Paris terror attacks. Political Psychology, 40(4), 679-704.

Wang, C.-H. (2016). Personality traits, political attitudes and vote choice: Evidence from the United States. Electoral Studies, 44, 26-34. https://doi.org/ 10.1016/j.electstud.2016.07.004

\section{About the Authors}

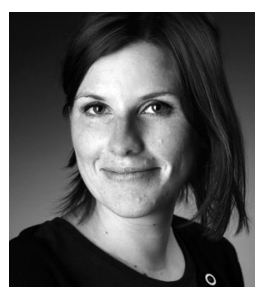

Sabrina Jasmin Mayer is Head of the Research Cluster Data, Methods \& Monitoring at the German Center for Integration and Migration Research (DeZIM) in Berlin and Senior Research Fellow at the University of Duisburg-Essen. She holds a PhD in political science. Her main research interests are comparative electoral behaviour, political psychology (especially personality traits and social identity), immigrant integration, and survey methodology.

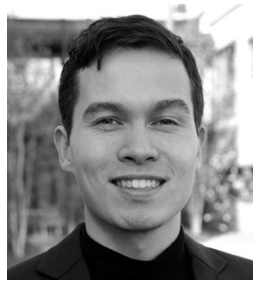

Christoph Giang Nguyen is a Lecturer at the Otto-Suhr Institute at the Freie Universität Berlin. He holds a PhD in political science from Northwestern University. His work focuses on the way that insecurity and disadvantage shape political attitudes and the way that emotions such as anger, anxiety, and disgust translate general grievances into specific political attitudes. He is also interested in research methods and research design, with a focus on experimental methods, large- $\mathrm{N}$ observational data, but also mixed-methods and qualitative research designs. 